\title{
Movimento feminista negro no país da democracia racial e da [des]igualdade
}

\author{
Clerislânia de Albuquerque Sousa ${ }^{1}$
}

\section{Resumo}

Este estudo pretende fazer uma abordagem bibliográfica acerca do feminismo negro e da sua importância no Brasil. Historicamente, o nosso país é marcado pelo legado da escravidão e as consequências mesmo após a abolição da escravatura são percebidas na atualidade. A ideia de que no Brasil a escravidão foi mais branda e que seus reflexos não são percebidos só ratifica com a ideia de que o mito da democracia racial foi uma ilusão a fim de esconder uma das maiores marcas da história do Brasil. Nesse contexto, este estudo pretende apresentar a importância do feminismo negro no que tange dar o protagonismo e o espaço que as mulheres negras merecem. O estudo revelou que o movimento feminista negro está em avanço, apesar das inúmeras barreiras, porém, a busca pelo seu espaço é um processo contínuo e permanente, visto que o Brasil e suas raízes históricas são configuradas pelo racismo.

Palavras-chave: feminismo negro; racismo; desigualdade.

\footnotetext{
${ }^{1}$ Mestre em Planejamento e Políticas Públicas - Universidade Estadual do Ceará / UECE. Email: clerislania@gmail.com

GT 09 - Gênero e relações étnico-raciais: as desigualdades e os desafios contemporâneos
} 


\title{
Black feminist movement in the country of racial democracy and [dis]equality
}

\begin{abstract}
This study intends to make a bibliographic approach about black feminism and its importance in Brazil. Historically our country is marked by the legacy of slavery and the consequences even after the abolition of slavery are perceived today. The idea that slavery in Brazil was milder and that its reflexes are not perceived only confirms with the idea that the myth of racial democracy was an illusion in order to hide one of the greatest marks in the history of Brazil. In this context, this study aims to present the importance of black feminism in terms of giving the protagonism and space that black women deserve. The study revealed that the black feminist movement is advancing, but the search for its space is a continuous and permanent process, since Brazil and its historical roots are shaped by racism.
\end{abstract}

Keywords: black feminism; racism; inequality.

\section{Introdução}

Pensar na trajetória do negro no contexto histórico e formação do nosso país pode ser um assunto muitas vezes tratado não com o interesse e destaque que ele merece. Tal imagem de coadjuvante e porque não "invisibilidade" pode ser interpretada como algo que procuram apagar na nossa história. Tal distanciamento não era de causar espanto, se pensarmos nas barbáries sofridas pelos negros, desde serem tirados à força de sua terra, as condições precárias da viagem, e, para os que conseguissem sobreviver ao trajeto até o Brasil passar a viver na condição de escravos.

Partindo-se para a situação das mulheres negras, o assunto ganha maior complexidade. Historicamente as mulheres escravas eram submetidas as mais diversas barbaridades de seus "senhores". "Os esforços de integração do negro na sociedade brasileira esbarram constantemente na ausência, por parte dessa mesma sociedade, de um projeto efetivo de integração social do negro" (CARNEIRO, 2019, p. 15). 
A abordagem de Suely Carneiro é bastante plausível, visto que historicamente a sociedade do Brasil, até então em construção, não visualizava o negro como uma pessoa bem vinda para a nação que até então estava surgindo.

Nesse sentido, compreende-se a importância deste estudo, uma vez que o fato da invisibilidade sofrida pelas mulheres negras impacta diretamente em inúmeras outras esferas da sociedade, onde podemos citar: emprego, saúde, educação entre outras. Tais abismos sociais que essas mulheres sofrem só podem ser redimidos através de politicas públicas e da busca por essas próprias mulheres do seu espaço e do seu protagonismo. Para esse estudo, buscou-se trabalhar com pesquisa bibliográfica, a fim de trazer autoras que abordam a temática do feminismo negro, a fim de trazer para o foco a discussão de um assunto que merece ser debatido por todos.

\section{Desenvolvimento}

A abolição da escravidão e a consequente inserção dos agora exescravizados em uma sociedade até então marcada pela dominação dos brancos, trouxe uma nova realidade, realidade essa que não poderia ser evitada. Schwarcz e Gomes (2018, p. 409), apresentam o que significava esse momento naquele período:

Nas ruas, um dito popular traduzia de forma sintética as novas modas intelectuais: "A liberdade é negra, mas a igualdade é branca" Um dia após a promulgação da Lei Áurea, a mais popular e a última do império, a Gazeta da Tarde estampou a chamada: "Liberdade é o dia da hoje". Liberdade se converteria então num conceito fundamental; num tíquete certo para a cidadania. Mas se mostraria também como um bem difícil de manter. A Primeira República, que se iniciava em novembro de 1889, prometeu inclusão social, porém acabou entregando muita exclusão. 
Apesar das tentativas de colocar a raça como fator secundário, o tema sempre teve bastante relevância, sendo "ainda hoje um conceito poderoso e persiste como construção histórica e social: matéria-prima para o discurso das nacionalidades e marcador social de diferença que identifica e classifica pessoas e situações" (SCHWARCZ; GOMES, 2018, p. 409).

O argumento que prevalecia da elite do período, no que tange a falta de oportunidades era explicado a fatores relacionados a classe e não à raça, uma vez que os não-brancos perecem os reflexos de seu passado como escravos, automaticamente, deixando-os em situação de desvantagem perante os brancos.

Acreditar que ocorreu, de fato, democracia racial no Brasil chega a ser uma afirmação contraditória segundo alguns estudiosos. Tal afirmação é "chancelada" devido a inúmeros exemplos que demonstram que pode ser acontecido tudo desde a abolição da escravidão, com exceção da democracia racial.

Moura (2019, p. 39) discorre sobre o assunto, onde coloca:

Queremos dizer, com isso, que houve uma reformulação dos mitos raciais reflexos do escravismo no contexto da sociedade de capitalismo dependente que a sucedeu, reformulação que alimentou as classes dominantes do combustível ideológico capaz de justificar o peneiramento econômico-social, racial e cultural a que ele está submetido atualmente no Brasil através de uma série de mecanismos discriminadores que se sucedem na biografia de cada negro.

Revisitando a história do negro no Brasil, o mesmo sempre esteve em situação de desvantagem. Quer seja na condição de escravo, vivendo em péssimas condições, ou na condição de liberto, sendo deixado à marginalidade, em uma sociedade marcada e enraizada pelo 
racismo. Partindo disso, corroborar com a ideia de que não houve racismo no Brasil gera inúmeros debates.

Antes de entrarmos no movimento feminista negro, faz-se necessário relembrar a condição de ser mulher negra no período da escravidão. Conforme convinha a seu proprietário, a mulher escrava era considerada como um trabalhador negro, ou então, como uma fonte reprodutora de mais escravos no futuro.

Tal comentário pode ser ratificado por Davis (2016, p. 17-9), onde:

O sistema escravista definia o povo negro como propriedade. Já que as mulheres eram vistas, não menos do que os homens, como unidades de trabalho lucrativas, para os proprietários de escravos elas poderiam ser desprovidas de gênero. [...] Uma vez que as escravas eram classificadas como "reprodutoras", e não como mães, suas crianças poderiam ser vendidas e enviadas para longe, como bezerros separados das vacas.

Além disso, a condição de ser mulher fazia com que as escravas sofressem abusos físicos e sexuais, os quais funcionavam como maneira de coerção. Sobre tal assunto, Davis (2016, p. 20) comenta:

Como mulheres, as escravas eram inerentemente vulneráveis a todas as formas de coerção sexual. Enquanto as punições mais violentas impostas aos homens consistiam em açoitamento e mutilações, as mulheres eram açoitadas, mutiladas e também estupradas. O estupro, na verdade, era uma expressão ostensiva no domínio econômico do proprietário e do controle do feitor sobre as mulheres negras na condição de trabalhadoras.

A partir dos comentários acima, percebe-se como a condição da mulher escrava foi de total barbaridade, ao passo que o pensamento feminista negro surge como um expoente de mudança e principalmente 
de empoderamento para um grupo social que sofreu no passado e que busca condições de igualdade perante a sociedade.

\section{Resultados e discussões}

O movimento feminista negro surge a partir de um desmembramento do movimento feminista e do movimento negro. Tal desmembramento é decorrente dos interesses diferentes dos movimentos.

Tal comentário pode ser corroborado por (SANTOS 2009 apud LEMOS 1997):

muitas mulheres negras passaram então a criticar a questão do machismo e sexismo por parte de seus companheiros militantes. Estas, ao mesmo tempo, tentavam organizar no interior do movimento suas próprias atividades, o que causava as mais diversas reações negativas por parte dos homens negros, tais como a ocupação intencional por parte destes das salas de reuniões nos dias em que as mulheres tinham suas atividades programadas. [...] tal situação criou uma disputa acirrada por espaço e poder entre homens e mulheres dentro do movimento, criando um clima de desconforto e apreensão.

Acerca dos impasses com o movimento feminista (SANTOS 2009 apud LEMOS 1997) coloca:

o principal desafio para o movimento de mulheres negras em 1970 era estabelecer quais eram as questões essenciais para as mulheres negras, de um lado, e qual seria a melhor forma de desenvolvimento e aplicabilidade dos conceitos feministas, com fins a organizar o feminismo negro. Para além desse aspecto, o feminismo negro era um conceito recente no Brasil 
Para as mulheres negras, a falta de interesse dentro do movimento feminista era uma das causas para a divisão do movimento. Nesse sentido, em meados da década de 80 o movimento feminista negro busca uma organização com suas próprias pautas, em busca do seu espaço e reconhecimento.

Sobre a criação do movimento feminista negro, Carneiro (2019, p. 167) coloca:

A mulher negra, no Brasil, a partir de meados da década de 1980, passa a se organizar politicamente em função de sua condição especifica do ser mulher e negra, por meio do combate aos estereótipos que as estigmatizaram; por uma real inserção social; pelo questionamento das desigualdades existentes entre brancas e não brancas em nossa sociedade; e contra a cidadania de terceira categoria a que está relegada por concentrar em si a tríplice discriminação de classe, raça e gênero.

Acerca de tal movimento, Carneiro (2019, p. 198) faz uma abordagem sobre o termo enegrecendo o feminismo, uma vez que utiliza tal expressão para:

Enegrecendo o feminismo é a expressão que vimos utilizando para designar a trajetória das mulheres negras no interior do movimento feminista brasileiro. Buscamos assinalar, com ela, a identidade branca e ocidental da formulação clássica feminista, de um lado; e, de outro, revelar a insuficiência teórica e prática política para integrar as diferentes expressões do feminismo construídos em sociedades multirraciais e pluriculturais.

Ao trazer à tona tais desigualdades, as mulheres negras colocam em foco inúmeras pautas do movimento, pautas essas em que as mulheres negras sofrem com o distanciamento de oportunidades e possibilidades de acesso em inúmeras esferas, tais como: saúde, educação, mercado de trabalho, dentre outras pautas do movimento. 
A partir da força que o movimento feminista negro vem ganhando ao longo dos anos, tais mudanças, decorrentes da ação do movimento, estão provocando inúmeras mudanças, dentre as quais Carneiro (2019, p. 217) elencam:

- o reconhecimento da falácia da visão universalizante de mulher;

- o reconhecimento das diferenças intragênero;

- o reconhecimento do racismo e da discriminação racial como fatores de produção e reprodução das desigualdades sociais experimentadas pelas mulheres no Brasil;

- o reconhecimento dos privilégios que essa ideologia produz para as mulheres do grupo racial hegemônico;

- o reconhecimento da necessidade de políticas específicas para as mulheres negras para a equalização das oportunidades sociais;

- o reconhecimento da dimensão racial que a pobreza tem no Brasil e, consequentemente, a necessidade do corte racial na problemática da feminização da pobreza;

- o reconhecimento da violência simbólica e da opressão que a brancura, como padrão estético privilegiado e hegemônico, exerce sobre as mulheres não brancas.

A partir do exposto, percebe-se a importância da inserção de tais questões para uma sociedade mais plural e justa, ao passo que o crescimento do movimento feminista negro em si mostra o espaço e o poder que essas mulheres possuem e o crescimento que estão buscando ao longo dos anos.

\section{Conclusões}


A partir deste estudo bibliográfico por possível observar como historicamente os negros sempre foram uma classe estigmatizada na histórica do nosso país. Mesmo após a abolição da escravidão, os negros continuaram carregando o estigma trazido pela sua cor da pele, tornando-se uma população indesejada para aquela nação em formação. No caso das mulheres negras, a situação ainda era mais complicada. Além da questão de ser escrava, as mulheres ainda eram abusadas sexualmente. Tais situações só caracterizam que o termo "mito" ao falar que houve no Brasil democracia racial não passa de uma grande ilusão.

Tais distanciamentos existentes na sociedade entre brancos e negros são reflexos diretos de um passado histórico marcado pelo racismo. Partindo disso, os movimentos sociais são cruciais para que tais desigualdades sejam minimizadas em uma sociedade tão marcada pelo individualismo. $\mathrm{O}$ movimento feminista negro possui suas pautas próprias e caminha em busca do seu espaço. A trajetória a ser seguida é longa, uma vez que o entendimento da reparação histórica que as mulheres negras devem ter deve ser compreendido pela sociedade como um todo. Essa mudança é urgente e necessária.

\section{Referências}

CARNEIRO, Sueli. Escritos de uma vida. São Paulo: Pólen, 2019.

CARNEIRO, Sueli. Racismo, sexismo e desigualdade no Brasil. São Paulo: Selo Negro, 2011

DAVIS, Ângela. Mulheres, raça e classe. São Paulo: Boitempo, 2016.

GONZALES, Lélia; HASENBALG, Carlos. Lugar de negro. Rio de Janeiro: Editora Marco Zero Limitada, 1982.

HASENBALG, Carlos. Discriminação e Desigualdades Raciais no Brasil. Belo Horizonte: Editora UFMG; Rio de Janeiro: IUPERJ, 2005.

MOURA, Clóvis. Sociologia do Negro Brasileiro. 2. ed. São Paulo: Perspectiva, 2019. 
MUNANGA, Kabengele. Rediscutindo a mestiçagem no Brasil - identidade nacional versus identidade negra. Petrópolis: Vozes, 1999.

SCHWARCZ. Lilia Moritz; GOMES, Flávio dos Santos (Org). Dicionário da escravidão e liberdade: 50 textos críticos. 1. ed. São Paulo: Companhia das Letras, 2018.

SCHWARCZ. Lilia Moritz. O espetáculo das raças: cientistas, instituições e questão racial no Brasil - 1870-1930. São Paulo: Companhia das Letras, 1993.

SCHWARCZ. Lilia Moritz. Sobre o autoritarismo brasileiro. 1. ed. São Paulo: Companhia das Letras, 2019.

SILVA, M. L. de A. M. Casa-grande \& senzala e o mito da democracia racial. $39^{\circ}$ Encontro Anual da Anpocs. Cadernos de Pesquisa, São Paulo, n. 79, p. $5-15,1991$.

SKIDMORE, Thomas E. Fato e mito: descobrindo um problema racial no Brasil. Cadernos de Pesquisa, São Paulo, n. 79, p. 5-15, 1991. 